\title{
Genitourinary System Infection
}

National Cancer Institute

\section{Source}

National Cancer Institute. Genitourinary System Infection. NCI Thesaurus. Code C35719.

An acute or chronic infectious process affecting any part of the genitourinary system. 